\title{
Pressure on Loan Officers in Microfinance Institutions: An Ethical Perspective
}

\author{
Debashis Sarker \\ European Microfinance Program (EMP), Solvay Brussels School of Economics and Management, University Libre de \\ Brussels, Belgium and Team Leader, BRAC Microfinance Programme, BRAC, Bangladesh. Email: \\ debashisemp@gmail.com
}

\begin{abstract}
Loan officers play diverse and significant role in Microfinance Institutions (MFIs). While performing their job, they encounter tremendous pressure. Some of the pressures are meeting deadlines and quotas, powerful hierarchical pressure, reducing Portfolio at Risk (PAR), working more than normal functioning hours in and outside office, structural pressure. These types of pressure reduce productivity, creates dissatisfaction with jobs, lower confidence, hamper relationship, and most importantly, impact personal life. This unrealistic pressure on loan officers is an ethical issue. In this paper, some management consequences will be discussed that arises from the unethical pressures. Besides that, some practical recommendation for the managers of microfinance institutions are suggested to address this issue such as proper implementation of human resource policy and procedures, appropriate planning and promote supportive culture, effective communication and feedback, adequate staff training and mentoring, following bottom-up approach, logistics support.
\end{abstract}

Keywords: Loan Officers/Credit officers, Pressure, Microfinance, Ethics

DOI: $10.7176 / J E S D / 4-12-84$

\section{Issue Definition and Objective:}

The job of loan officer is challenging and critical in the microfinance institutions (MFIs). Loan officers work as an intermediary between microfinance institutions and clients. Loan officers are front line staff and they spend most of the times with clients. Their direct communication allows them to see, hear or even experience the need of the clients (Gray, 2013). Considering different methodologies such as group lending or individual lending in microfinance, loan officers are mainly in charge of screening potential customers, loan applications, continuous monitoring and follow up of the loans, producing required reports (Holtmann \& Grammling, 2005; Labie et al., 2009). Loan officers take a major role in selection of clients who will be receiving finance finally (Labie et al., 2009; Agier and Szafarz, 2011). The performance of microfinance institution vastly depends on the success and failures of loan officers. If they fail, microfinance also fails with them especially for group based lending (Dixon et al., 2007).

However, in many cases, loan officers get enormous pressure from the higher management on different issues such as disbursing more loans, new clients' selection, and repayment collection. Moreover, loan officers always face an inherent tension as they consider the wellbeing of the clients; on the other hand, they also have a stake in the successes of their employers (Gray, 2013). Beyond following rules and policies of the organizations, sometimes they need to compromise many things especially when it requires meeting with the expectation of the organization. Naturally, loan officers do a numerous work outside of their regular and usual work hours. Despite of the high workload and time, loan officers might be fired by the organization when they smash the rules (Gray, 2013). The priorities of today's organizations are to attract and retain meritorious and talented employees. These employees might have a positive impact of the performance of the organizations (Saleem, 2011) but due to unethical pressure, loan officers cannot perform their job ethically all the times. However, the main objective of this paper is to discuss how loan officers in MFIs are experiencing unethical pressures and to identify some management consequences resulting from those pressures. Finally, some practical recommendations for managers to reduce those pressures are discussed.

\section{Issue Description:}

Pressure on loan officers is an ethical issue in microfinance institutions. Every individual needs to be treated with respects in the workplace. However, sometimes individuals have to face unfavorable working environment and might be affected by the weak planning of the organization. Loan officers of microfinance institutions face these kinds of issues regularly. The absence of remedial measure or consideration of the effect of issues related to ethics on the workplace environment leads to reduced output and dissatisfaction with work, hamper intra and interrelationship in the workplace, lower confidence, affect personal life, reduce respect on rules and values of the organization, stimulate malpractices in the operation. Due to all these reasons, lowered efficiency and performance is the first sign of a stressful atmosphere.

The employer-employee relationship should not be seen at simply in the economic terms rather it should be an important human relationship of mutual understanding and reliance, which could have greater impact on all the people associated. In addition, both employee and employer should produce some moral obligation resulting from this relationship. However, severe unexpected and unrealistic pressure is putting on the shoulder of loan officers. Sometimes pressure is artificially created to achieve a harmful objective of the organization. According to Leka et al. (2003), pressure is quite common in the workplace because it is the command of the modern-day workplace. 
Excessive pressure or sometimes-unmanageable pressure creates stress. Stress could generate from the way job is designed and managed and the way institution's internal system is developed. Stress could be bad for staff's health and performance of the business. Stress might also arise from the weak management, working conditions without satisfaction and absence of support from co-workers as well as supervisors. Loan officers want to leave their jobs because of the extreme pressure from their organizations and unusual situation they face dealing with the group of clients. Moreover, loan officers start behaving negatively to keep their performance better and show their positive achievement to the organizations. However, when clients do not repay on time then loan officers become victim of the situation (Gray, 2013).

\section{Literature Review:}

Almost no academic paper is written specifically on the issue of the pressure on loan officers in microfinance institutions from an ethical point of view. Researchers mainly focused on loan officers' activities and ethical challenges in microfinance practices. However, loan officers experience a tremendous pressure for meeting deadlines. When the deadline comes close, loan officers lose their focus on the given task due to the pressure. They face pressure to meet up deadline of loan disbursement, loan recovery, admitting new clients, overdue collection. Senior managers or supervisors of microfinance institutions always keep pressure on loan officers for attaining the operational achievement. Loan officer faces powerful hierarchical accountability pressure in the organization and experience hardship to deal with clients for loan repayment (Dixon et al., 2007).

Some MFIs have desperate expansion strategy. These MFIs want to expand rapidly and increase the number of loans and the size of loans without considering the quality of the loan portfolio. To achieve the objective of rapid expansion, microfinance institution's higher management makes the plan and pushes it to the frontline officers, which ultimately goes to the loan officers. For meeting the demand of the management of the MFIs and to protect themselves from the pressure, loan officers provide loan to many clients without considering the reality of the customers capacity. MFIs also want to reduce costs especially relevant to loan officers. One of the ways to reduce cost per loan officer is when loan officer provide loan to many customers. MFIs might get benefits out of this strategy but this strategy also decreases the quality of the loan portfolio and quality of the staff. Thus, loan officer provides loan to clients who are realistically unable to pay back (Munir, 2012). For increasing the operational coverage, loan officers face serious pressure to achieve their quotas.

Loan officer are expected to maintain high profitability. Investors always want to see MFIs to do well in terms of international profitability standards. This motive directly influences to reduce labor cost and enhance staff productivity. This also create another pressure on loan officers. An extra pressure that loan officers' face is to manage PAR (Portfolio At Risk) rate. They always want to reduce this rate and due to that, they do unethical practices. This is also happening as donors and funders judge them accordingly (Khan, 2012). Loan officers do not only face pressure from employers, or target but also face a serious pressure to pay their own money to recover the overdue amount. This statement is reflected in another paper which states that loan officers also face pressure to repay arrears of clients from their own remuneration (Armendariz \& Morduch, 2010). Moreover, loan officers usually works with insufficient resources.

Loan officers usually work hard and sometimes they are bound to work until night. Due to the nature of the job and direct involvement with the clients, loan officers spend $75 \%$ of their working time outside of their office (Holtmann \& Grammling, 2005). Sometimes the role of loan officers contradicts with the policies of the MFIs. In microfinance practices, standardize and automate decisions for lending creates enormous challenges to loan officers' capabilities to manage clients. Centralized policies cannot be implemented because of the uncertain context in the practical field or at the operational level (Canales, 2012). Pressure for doing work, especially when to achieve unrealistic target, could create breakdown in ethical judgment. Loan officers are sometimes not prepared for a job that leads them to do badly behave with clients especially when clients are unable to repay installment on time. However, clients also suffer at the end due to the failure of repaying dues on time in many cases.

Sometimes loan officers receive very short-term ethical orientation through training sessions as a cross cutting issues or discussion from the higher or relevant management of the organization. With a small guidance on the ethical orientation, loan officers sometimes violate the ethical concern just for recovering dues from clients. Treating badly with clients is not a policy but respecting clients is a mantra. However, this mantra does not work always specially when there is a bad performance of loan portfolio (Wardle, 2011). MFIs always try to reduce staff costs by standardizing of policies which create another pressure on loan officers. Technology based procedures and standardization can restrict the decision of the loan officers. As a result, these things enhance structural pressure on loan officers (Canales, 2012).

\section{Management Consequences:}

Unethical pressure creates multiple consequences in the organization. Due to this, the quality of microfinance operation becomes questionable. Loan officers do not spend required time to ensure portfolio quality, hide information to the peer colleagues and to the organization, which eventually lead to the worst situation. For keeping portfolio quality, sometimes MFIs introduce incentives to motivate their front line staff such as loan officers but it might not work always. Loan officers might have a limitation in their capacity to manage extreme workload. These pressures do not only reduce staff productivity but also influence employer-employee relationship, complicate the image of the organization to internal and external stakeholders. Following are the some of the management consequences of unethical pressure on the loan officers: 
* Diminish staff's productivity and causes of high turnover: Due to the heavy workload, loan officers usually pass busy time. During the time of pressure, they cannot focus on the proper planning of their work, experience challenges to set strategic goal and become confused to cope up with stress. This is how pressure reduces staff productivity. Besides that, pressure is one of the causes of high turnover. Some organizations are always creating a threatening environment against staff's bad performance. If loan officers do not perform up to the expectation of the organization, then organization sometimes fire them. These types of threats always create frustration and make loan officers less efficient. Thus, the result is high turnover.

* Hinder portfolio quality, affect credit culture and long-term sustainability: When loan officers are under pressure, they try to provide loan to many clients. Due to this, loan officers select bad clients to provide loan. They ignore the procedural bindings of the organizations to screen clients and disburse loan. Primarily, it may appear that loan portfolio quality is good but eventually it could drastically affect the portfolio at any time in the near future. Pressure could create corruption and force loan officers to involve into the fraudulence activities that could ultimately affect the credit culture of microfinance institutions. Unrealistic pressure could distress long-term sustainability of MFIs.

- Obliterate image of the institution and stimulate unethical practice: Unethical pressure leads to the loan officers to misbehave with customers while collecting repayments. Sometimes loan officers collect household goods of the clients due to the client's failures of the repayment and loan officers create unnecessary panic to customers. This is how it produces negative image to the clients and communities as well as other stakeholders such as investors or donor organizations. On the other hand, for meeting the extra burden of expectation, loan officers become involve with misappropriation and corruption.

* High-pressure affect customers: After pressurized from organization, loan officers provide big size loan to clients without considering the capacity of the clients and keep pressurizing clients for loan repayment. Due to this, poor clients usually get loan from other MFIs to repay the present loan and then clients might become over indebted for following the same processes for further repayment of loan. This cycle might create an environment when clients have nothing to repay anymore and eventually put them into credit trap. This situation might force clients to commit suicide as we can remember the incident that took place at Andhra Pradesh, India in 2010, where many microfinance clients committed suicide due to the pressure from the organization for repayment.

* Affect employee-employer relationship: Good relationship between employee and employer which is based on the ethical premises is crucial for the success of an organization. Unethical pressure leads to disrespect existing employeeemployer relationship. Employees do not feel ownership in their assigned job and create negative perception to the organization. Thus creates mistrust and affect normal relationship in the workplace.

\section{Practical Recommendations}

To address negative management consequences, MFIs can focus on several areas to avoid or reduce unethical pressure on loan officers. The effective measures could be from initiating and implementing internal to external mechanisms. If MFIs successfully handle this type of unethical pressure in the workplace then the benefits would ultimately go to the hands of all parties involved in the organization. Effective human resource policies and necessary supportive culture, proper communication among the staff, setting realistic target, ensuring intra and inter relationship of employees could be some of the tools to reduce the pressure. Here are some of the possible practical recommendations to deal with the situation especially for managers of MFIs:

* Effective Implementation of Human Resource Policy and Procedures (HRPP): Managers of MFIs might initiate HRPP and respect to those procedural issues for all staff of the organization. Code of conducts and ethical behavior of the staff could be included in the policies. All issues related to staff, program operation and organizational support should be specified in an understandable way so that employees can get the exact meaning of the policies. However, managers also should provide sufficient time to monitor the progress of the implementation. Besides that, an internal team could be formed from the existing management staff of the organization that will look after the implementation of all the procedural issues. If any deviation occurs then the team could treat the case in a flexible way with logical perspective to adjust with the need of the time, work place environment and frequency of the incidents.

* Supportive management and diversification of workload: Managers could create supportive attitude culture such as creating environment for job satisfaction, less stress for directing staff. This supportive culture could give some motivation to its employees in the organization. Besides that, managers should not put all the responsibilities on the shoulders of loan officers especially for dealing with clients. Loan officers could work for screening clients and approving loan but there could be other unit or people to do the job of repayment collection. This might increase some costs for the organization but at the same time also might save money especially in the case when existing corruption level becomes very limited or zero. However, proper balance of responsibilities could create work friendly environment that would ultimately reduce pressure. 
* Enhance better communication and feedback: Managers can ensure effective communication regarding strategic decisions through organizing meetings and field operation visits so that every staff can understand the organizational policies and objectives. Managers should create favorable environment so that loan officers can raise questions about difficulties they face in the microfinance operation. Managers could also organize feedback sessions for loan officers regarding their activities and performance maintaining regular intervals. Organizing open session could be very useful tool to do some internal research on multiple issues and analyzing all those information could open new ideas for the managers for designing strategies.

* Bottom-up approach and realistic target set-up: Managers should not set target by following only top-down approach. They have to be realistic in designing different targets such as loan disbursement, admitting new clients', repayment and overdue collections. Managers should also be consultative with loan officers before setting target so that loan officers could be committed for attaining their target. For avoiding this unethical pressure, managers should be more realistic before taking any decisions or setting any financial target.

* Strengthening employer-employee relationship and ensuring fearless environment: Good relationship between employees and employers and fearless working environment might satisfy loan officers and support loan officers to feel out of pressure while doing their daily job. Managers should work strategically to build profitable relationship with loan officers. Loan officers are always under pressure to lose job anytime in the most complex working environment. However, managers could ensure fearless and comfortable working environment by transparency, effective communication, introducing incentives and rewarding staff who have good performances with high ethical standards.

* Supply necessary logistics support for monitoring clients: Sometimes loan officers' need to move long distance and remote areas for group meeting with clients, visiting individual clients, and repayment collections. For doing so, they need necessary logistics supports. Managers should provide necessary transportation or allowances. Managers should not treat loans officers as robots or machines. Redesigning or merging of clients' credit groups or branch offices could play a significant role to reduce these types of hassles.

* Provide need based training on stress management and competency as well as initiate mentoring program: Managers should fix logical financial and non-financial budgets for loan officers training on different issues such as developing competency, dealing with delinquent clients, time management, stress management and other soft skills training. These kinds of training could help loan officers to prepare themselves to face challenges in the workplace. Mentoring is another crucial issues specifically for new and women staff. Managers can introduce mentoring program for the new and existing staff so that proper guidance and advice are available to all staff.

\section{Conclusion:}

Loan officers offer their best to make the business successful for the organization. Their role is multidimensional in the organization's work environment. It is evident that in every job responsibilities, there exist pressures. However, the issue is whether these pressures are within the limit or out of limit. When unnecessary and irrational pressure creates substantial miseries for loan officers then it becomes very unethical. Loan officers in MFIs expect to get respect in the workplace. If loan officers get required attention from the organization and supervisors, their pressure could be minimized in a substantial way that will make loan officers to feel proud of their work. Sometimes unethical pressure leads them to evade their own moral values. For ensuring sustainability of the organization, reputation, achieving desired ethical objectives, managers of MFIs should be more proactive to deal with these ethical issues.

\section{References:}

Armendariz, B. and J. Morduch. (2010). The Economics of Microfinance, $2^{\text {nd }}$ Edition, MIT Press, Cambridge.

Agier, I. and A. Szafarz. (2011). Credit to Women Entrepreneurs: The Curse of the Trustworthier Sex, CEB Working paper N. 11/005, University Libre de Bruxelles-Solvay Brussels School of Economics and Management, Belgium.

Agier, I. and Assuncao, J. (2009). The role of credit officers in the performance of microcredit loans: evidence from Vivacred in Brazil, retrieved from http://www.microfinancegateway.org/gm/document-1.9.41334/13.pdf

Canales, R. (2012). The Stranger as Friend: Loan Officers and Positive Deviance in Microfinance. Using a Positive Lens to Explore Social Change and Organizations: Building a Theoretical and Research Foundation, 431.

Dixon, R. and Ritchie, J. and Siwale, J. (2007). Loan officers and loan delinquency in microfinance: a Zambian case. Accounting Forum, 31 (1). Pp. 47-71, p.1-26 
Gray, B. (2013). Voices from the frontlines: A Research Project Focused on Listening to Microfinance Credit Officers, Working paper, Freedom from Hunger. Retrieved from https://www.freedomfromhunger.org/sites/default/files/Voices_Frontlines_Final_Report_3-1-2013.pdf

Holtman, M. and Grammling, M. (2005). ‘A Toolkit for designing and Implementing Staff Incentives Schemes', Microfinance Network and CGAP.

Khan, M.M. (2012). 'Microfinance is Down, But Not Out', Society and Culture: Huffington Post: Impact Blog, retrieved from http://www.huffingtonpost.com/moushumi-m-khan/microfinance-is-down-but-_b_1773696.html, accessed on: 15.04. 2013.

Labie, M., Meon, P-G, and A. Szafarz. (2009). Discrimination in Microfinance: The role of credit officers, CEB Working paper N 09/017, University Libre de Bruxelles-Solvay Brussels School of Economics and Management, Belgium.

Leka, S., Griffiths, A., and Cox, T. (2003). 'Work Organization and Stress: systematic problem approaches for employers, managers and trade union representatives', Protecting workers' health series; no.3, World Health Organization: Geneva. retrieved from http://www.who.int/occupational_health/topics/stressatwp/en/

Munir, K. (2012). Akhuwat: Making Microfinance work, A ground breaking microfinance model is bringing out the best in society, Stanford social and innovation review blog. retrieved from http://www.ssireview.org/blog/entry/akhuwat_making_microfinance_work

Saleem, S. (2011). The impact of Financial Incentives on Employees Commitment, European Journal of Business and Management, Vol 3, No. 4.

Wardle, L. (2011). The Hardest-Working People in Microfinance, Center for financial inclusion blog, Accion. retrieved from http://cfi-blog.org/2011/11/02/the-hardest-working-people-in-microfinance/

\begin{abstract}
About the Author: The author is a CUD scholar and studying European Microfinance Programme (EMP) at the Solvay Brussels School of Economics and Management, University Libre de Brussels, Belgium. He is also working at BRAC Microfinance Programme, BRAC (www.brac.net) in Bangladesh but currently on study leave. He was born and bred in Bangladesh. He did Bachelor in Business Administration (BBA) and Master in Business Administration (MBA) from University of Dhaka, Bangladesh.
\end{abstract}

Dedication: This article is dedicated to my respected uncle Dr. Sukumar Sarker and Aunty Aloka Rani Sarker and my lovely cousins: Aparna Sarker, Subarna Sarker, Alpana Sarker \& Pranab Sarker. 